\title{
Los nuevos movimientos sociales y las ciudadanías emergentes: reflexiones desde el concepto de democracia radical y el movimiento LGBTI en Colombia
}

\author{
The New Social Movements and the Emerging Citizenries: \\ Reflections from the Concept of Radical Democracy and the LGBTI \\ Movement in Colombia \\ Os novos movimentos sociais e as cidadanias emergentes: reflexões \\ desde o conceito de democracia radical e o movimento LGBTI \\ na Colômbia
}

\section{Nina Ferrer Araújo*}

FECHA DE RECEPCIÓN: 17 DE JUNIO DE 2015. FECHA DE ACEPTACIÓN: 31 DE MARZO DE 2016

DoI: http://dx.doi.org/10.12804/revistas.urosario.edu.co/sociojuridicos/a.4025

Para citar este artículo: Ferrer Araújo, N. (2017). Los nuevos movimientos sociales y las ciudadanías emergentes: reflexiones desde el concepto de democracia radical y el movimiento LGBTI en Colombia. Estudios Socio-Jurídicos, 19(1), 43-62. Doi: http://dx.doi.org/10.12804/revistas.urosario.edu.co/sociojuridicos/a.4025

\section{RESUMEN}

El presente texto, es un artículo de reflexión que constituye parte de la base teórica del Proyecto de Investigación denominado "Ejercicio del derecho al trabajo de la población transgenerista de la ciudad de Cartagena: análisis de las condiciones laborales frente a los estándares de trabajo digno", que incluye el análisis del caso concreto en uno mucho más general: la ciudadanía trans en el Distrito, como una identidad colectiva en construcción en la que los patrones de represión y violencia han constituido un punto importante de acción y reacción, entendiendo la identidad transgénero como una de las presentes en el Movimiento Social LGBTI de la ciudad y de Colombia. Para tales fines será necesario abordar un breve desarrollo teórico del concepto de ciudadanía, para entrar en el campo de la acción colectiva y los movimientos sociales como agencias de democracia radical, so pretexto de comprender la articulación entre el movimiento social y la consecución del estatus ciudadano de la población transgénero, asunto que, a pesar de los avances

* Abogada de la Universidad de Cartagena, especialista en Derecho Comercial de la Universidad Libre de Cartagena, diplomatura superior en Ciencias Sociales y magíster en Género, Sociedad y Políticas Públicas de la Flacso- Buenos Aires, Argentina. Docente de la Fundación Universitaria Tecnológico Comfenalco y de la Universidad San Buenaventura de Cartagena. Correo electrónico: nferrer@tecnologicocomfenalco.edu.co y almash7@hotmail.com 
democráticos a partir de la Constitución Política de 1991, continúa siendo conflictivo, principalmente porque la ciudadanía trans es reconocida de manera incompleta.

Palabras Clave: Ciudadanía, democracia radical, ciudadanías emergentes.

\section{ABSTRACT}

This text is a reflection article part of the theoretical basis of the research project called "Exercising the right to work of Cartagena city's transgender population: analysis of the working conditions regarding the standards of decent work", which embeds the analysis of the case in a much more general one: trans citizenship in the District, as a collective identity construction in which acts of repression and violence have been an important point of action and reaction, understanding transgender identity as one of those present in the LGBTI Social Movement in the city and in Colombia. For such purposes a brief theoretical development of the concept of citizenship will be addressed, to enter the field of collective action and social movements as agents of radical democracy, on the pretext of understanding the links between social movements and the realization of the transgender population citizen status, a matter which, despite the democratic advances since the 1991 Constitution, remains controversial, because trans citizenship has been recognized in an incomplete way and in some cases only by the use the legitimate force.

Keywords: Citizenship, radical democracy, emerging citizenship.

\section{RESUMO}

O presente texto, é um artigo de reflexão que constitui parte da base teórica do Projeto de Investigação denominado "Exercício do direito ao trabalho da população transgênero da cidade de Cartagena: análise das condições laborais frente aos standards de trabalho digno", incrustando a análise do caso concreta em um mais geral: a cidadania transgênero no Distrito, como uma identidade coletiva em construção na que os patrões de repressão e violência têm constituído um ponto importante de ação e reação, entendendo a identidade transgênero como uma das presente no Movimento Social LGBTI da cidade e da Colômbia. Para tais fins será necessário abordar um breve desenvolvimento teórico do conceito de cidadania, para entrar no campo da Ação coletiva e os movimentos sociais como agências de democracia radical, sob pretexto de compreender a articulação entre o movimento social e a consecução do status cidadão da população transgênero, assunto que, apesar dos avanços democráticos a partir da Constituição Político de 1991, continua sendo conflitivo, principalmente porque a cidadania transgênero é reconhecida de maneira incompleta e em alguns casos, só através do uso de vias de fato legítimas por parte de seus integrantes.

Palavras-chave: Cidadania, democracia radical é cidadanias emergentes. 


\section{Introducción}

Es un hecho histórico que la perspectiva de ciudadanía ligada al Estado Nación y al devaluado concepto de igualdad del liberalismo no se ajusta a las necesidades de los Estados de hoy en los que coexisten diferentes etnias, distintas naciones y distintos grupos representativos de necesidades e intereses. Esto supone también que la idea de democracia como gobierno de las mayorías tampoco satisface esa situación porque el concepto de mayoría es sumamente excluyente. Por tales razones han tomado fuerza las teorías que propugnan por una democracia radical que entiende la ciudadanía como una forma de identidad política basada en la identificación con los principios del pluralismo, es decir, en la afirmación de la libertad y la igualdad para todos y todas.

La ciudadanía de hoy, no es solo una identidad entre otras, como en el liberalismo, ni es la dominante que anula a todas las demás, como en el republicanismo cívico (Mouffe, 1992, p. 9), es una identidad política común entre personas comprometidas en muy diversas empresas y con diferentes concepciones del bien, pero vinculadas las unas a las otras por su común identificación con una interpretación dada de un conjunto de valores ético-políticos.

En una democracia radical es donde puede entenderse la ciudadanía como un concepto articulador de las diferentes posiciones del agente social -concilia los intereses comunes y las libertades individuales-, es por ello que la ciudadanía plena LGBTI solo es posible en un Estado radicalmente democrático, donde los grupos que históricamente han sido discriminados alcanzan el estado de completitud en el reconocimiento y ejercicio libre de sus derechos.

\section{Metodología}

El Proyecto de Investigación del que nace este texto se diseñó con carácter socio-jurídico, enfoque mixto y alcance descriptivo, previendo el uso de diversas técnicas de recolección de información, tales como entrevistas, encuestas (tipo sondeo de opinión) y observación, que al finalizar fueron objeto de triangulación. No obstante, hay que aclarar 
que lo presentado en el texto, es producto de una primera fase, eminentemente documental, en la que a partir del método hermenéutico se abordan categorías que sirvieron de fundamento para el análisis de los resultados del trabajo de campo.

\section{Avances}

\section{Evolución del concepto de ciudadanía: un proceso cargado de exclusión desde la Polis Griega, el Estado Nación y las Sociedades Posnacionales}

La ciudadanía históricamente representa la consecución de derechos a los particulares, frente al alguna vez omnímodo poder estatal en las diversas definiciones que se han intentado, se encuentra como rasgo común su relación con un contenido de derechos reconocidos $\mathrm{u}$ otorgados (dependiendo desde la perspectiva de la que se hable) por el Estado, que se ejercen en primera medida en el territorio correspondiente al mismo e incluso por fuera de él, en la medida en que hoy han adquirido autonomía por encima de la soberanía territorial.

El concepto de ciudadanía en las civilizaciones griega y romana

El origen de lo que hoy entendemos por ciudadanía proviene de dos enfoques distintos, uno fruto de la tradición democrática ateniense y otro desde la jurídica romana. La tradición ateniense como proyecto de gobierno, pregonaba la importancia que todos los ciudadanos tienen para la Polis, pero especialmente resalta a esta como principal espacio del ciudadano, de manera que su actuar debe orientarse a garantizar la seguridad de la misma. Recordemos que el primer autor en sistematizar el concepto de ciudadanía en la antigua Grecia fue Aristóteles, quien percibía que la ciudadanía supone una cierta comunidad, de manera que los dos espacios más importantes de desarrollo son la familia y la ciudad:

La ciudadanía supone una cierta comunidad, vivimos con los demás y eso todo ciudadano siempre debe tenerlo en cuenta. La convivencia 
es una necesidad: "el que no sabe vivir en sociedad es una bestia o un dios". Pero para vivir en sociedad necesitamos de la ética y de la moral, únicas vías para poder conocer y desarrollar la virtud ciudadana. Y es que sin virtud el hombre "es el animal más impío y más salvaje, y el peor en su sexualidad y su voracidad. La justicia, en cambio, es algo social". El objetivo superior de todos los ciudadanos debe ser el mismo: la seguridad de la polis (Aristóteles citado por, Horach, 2009, p. 2).

Ahora bien, el concepto de ciudadanía ateniense no fue siempre el mismo, se transformó de igual manera que lo hizo la democracia, desde las reformas Solónicas, las posteriores de Clístenes y el periodo radical de Pericles, siempre de manera progresiva hacia una democratización de las relaciones entre la polis y los ciudadanos'.

El concepto de igualdad en la sociedad ateniense ha inspirado a lo largo de la historia cuantos modelos de democracia participativa se han formulado, entendida en su doble acepción como el derecho de todos los ciudadanos a hablar en la Asamblea de Gobierno (isegoría) y la igualdad llana frente a la ley (isonomía) (Cortina, 2013).

De la misma forma que el modelo inspiró con sus virtudes, lo hizo con sus limitaciones, transmitiendo muchas de ellas a las formas actuales de ejercicio de la ciudadanía. La primera de estas limitaciones es el hecho de que la ciudadanía era exclusiva y no inclusiva, solo eran ciudadanos los varones adultos cuyos progenitores también hubieran sido ciudadanos atenienses, excluyendo de "privilegios" a mujeres, niños, metecos (extranjeros) y esclavos. Segunda, y consecuencia de lo anterior, la concepción bipartita de igualdad era aplicable a todos los ciudadanos más no a todos los seres humanos. Finalmente, la participación directa o lo que se ha llamado democracia congregativa solo ha demostrado su eficacia en pequeñas sociedades y no en los grandes imperios (Cortina, 2013).

Del otro lado de la orilla, el modelo romano de ciudadanía se construye a partir de una situación completamente diferente, marcada en primera medida por la vasta geografía del imperio, ser ciudadano romano era poseer una categoría o estatus legal más que el vínculo político ateniense,

En el concepto griego de ciudadanía es necesario y obligatorio que se compartan los espacios de trabajo entre lo público y lo privado. Esto quiere decir que el buen ciudadano es el que participa activamente en la Polis. 
la ciudadanía romana genera un vínculo con un sistema jurídico. Este vínculo se presenta en diversos grados: "Por ejemplo, se permitía a los esclavos que en algún momento pudieran conseguir esta condición, y también podían tener acceso a ella individuos pertenecientes a las tierras conquistadas por el imperio" (Horach, 2009 p. 7). No obstante, de la misma forma que se atribuían derechos a los ciudadanos romanos se les imponían deberes producto de esta relación, pero no deberes políticos como los atenienses, sino básicamente el deber del servicio militar y del pago de los impuestos.

\section{El olvido de la ciudadanía durante la Edad Media}

No se encuentran evidencias históricas que demuestren que, hasta llegada la modernidad, el concepto de ciudadanía haya tenido la importancia que tuvo en Grecia y Roma, lo que se explica lógicamente por el abandono de la democracia y de la idea de participación; si bien se ha mencionado que la intervención en la vida pública era un tema importante para los atenienses, no lo era para el cristianismo que dominó ideológicamente durante la Edad Media. El cristianismo suprime la importancia de la ciudadanía como estatus, de hecho, Agustín manifestó que la finalidad del hombre no era atenerse a los deberes ciudadanos sino rezar (Citado por Horach, 2009 p. 10), alejándose de la visión Aristotélica, que solo se recupera a partir de Tomás de Aquino ya en el siglo XIII.

\section{Formación de un concepto de Ciudadanía Nacional}

Posteriormente, al finalizar la Edad Media, con el auge de las ciudades Estado en Italia, se produce un vuelco al concepto de democracia, en la medida que el reconocimiento de derechos y el estatus de ciudadanos se afinca comúnmente en la posesión de bienes, de producción y capital, generando la fortaleza de una clase social que posteriormente impulsaría las dos grandes revoluciones del siglo XVIII, la Norteamericana de 1776 y la Francesa de 1789, ambas cimentadas en el lenguaje de derechos ${ }^{2}$ y

\footnotetext{
2 Es de anotar que estas dos perspectivas de ciudadanía provienen también de las tradiciones encontradas de Grecia y Roma.
} 
en el concepto de nación. Sin embargo, una de ellas, la primera, mejor vinculada con el concepto de democracia participativa y por tanto tendiente a la tradición republicana, y la segunda, más cercana a la democracia representativa propia de la ciudadanía liberal.

Lo cierto es que el concepto de ciudadano en una y otra revolución lo podemos fusionar en el de ciudadanía nacional, entendida como ese vínculo existente entre el ser humano y la nación a la que pertenece, donde esta es "una comunidad acuñada por una raíz común, con un lenguaje, una cultura e historia comunes, a la que acompaña un requisito indispensable: la voluntad de sus componentes de configurarse como nación" (Cortina, 2013, p. 51), que tratándose de la ciudadanía republicana insiste en los derechos políticos (revolución norteamericana), y en el de ciudadanía liberal (revolución francesa) enfatiza la necesidad de reconocimiento y garantía de los derechos civiles.

La tesis de T.H. Marshall de la Ciudadanía alrededor de los derechos humanos

Uno de los autores que goza de mayor reconocimiento en materia de teoría de la ciudadanía, es T.H. Marshall, quien ofrece una definición que incluye no solo los derechos civiles y políticos, sino también los derechos sociales. Marshall (1950) definió la ciudadanía como el máximo estatus reconocido por el Estado a sus asociados y la dividió en tres: la ciudadanía política, la civil y la social; para cada ámbito identificó unos derechos e instituciones.

La ciudadanía política, se puede simplificar en la frase común, derechos a elegir y ser elegidos/as, su institución, los parlamentos y cargos de elección popular de las municipalidades; la ciudadanía social, garantizadora del bienestar económico, del derecho a participar del patrimonio social y vivir una vida conforme a los estándares corrientes de la sociedad, la institución bandera, el sistema educativo y los servicios sociales; y finalmente la ciudadanía civil, necesaria para el reconocimiento y desarrollo de las libertades básicas del individuo, incluye todas las libertades, el derecho de propiedad, a celebrar contratos y obviamente el acceso a la justicia en defensa de estos derechos, la institución clave 
para esta ciudadanía son precisamente los tribunales de justicia (Ferrer, 2010 p. 115).

Esta ciudadanía social acuñada por Marshall, se corresponde con el desarrollo del Estado de bienestar que, siguiendo las reflexiones de Adela Cortina (2013), correspondió a un esfuerzo histórico de los Estados Nacionales de la Europa de finales del siglo XIX por tratar de disminuir el impacto de las tesis socialistas y las reivindicaciones de la clase obrera, dando mayor nivel de satisfacción a los trabajadores para legitimar el poder del Estado, indiscutiblemente impactado por la depresión económica y las teorías de Keynes. Frente a este Estado, se han hecho muchas críticas, ya que si bien el moderno se caracterizó por ser indiferente, este al otro extremo, se ha vuelto asistencial, generando unas nuevas formas de relaciones de la ciudadanía concentradas en el exigir para recibir.

La crisis del Estado Bienestar da paso, por un lado, a retomar los conceptos individualistas del Estado liberal de Derecho, asumiendo nuevamente el papel protagónico el ciudadano, antes que la ciudadanía colectiva y, por el otro, al diseño de un Estado social de derecho, en la que la ciudadanía deja la costumbre de recibir para adquirir la costumbre de participar. De hecho, si se ve con ojo crítico, el concepto de Marshall de ciudadanía, es un asunto de titularidad de derechos, frente a la propuesta del Estado social de derecho que además incluye la responsabilidad de ejercerlos.

\section{Modelos históricos de ciudadanía}

Todo el recuento de las páginas anteriores se circunscribe a la evolución histórica del concepto de ciudadanía, a partir del cual se desarrollaron unos modelos defendidos por diversos autores. A continuación se hace un esfuerzo académico por sintetizar de manera práctica cada uno de los modelos identificados.

- Modelo Liberal de Ciudadanía: desarrollado por autores franceses del siglo XVII, entre los que podemos destacar a los clásicos Jean Jaques Rousseau y Maximilien Robespierre, propio de los Estados Liberales de Derecho nacientes en la modernidad europea parte de una visión 
individualista del ciudadano, razón por la cual los derechos individuales son la principal concesión que se le hace a quienes integran la categoría de ciudadanos. El concepto de participación política es restringido en cuanto a quienes lo pueden hacer (no cobija las minorías excluidas ni a las mujeres), y en lo relativo a la forma de participar, por lo tanto se trata de una forma de democracia predominantemente representativa.

- Modelo Republicano de ciudadanía: esta forma de ciudadanía también encuentra relación con el Estado de derecho de la modernidad, pero no con el Estado Europeo sino con el Estado Naciente de la Emancipación Norteamericana. Desarrollado fuertemente por autores tales como Hannah Arendt y Philip Pettit, entre otros, comprende al ciudadano como una esencia deliberativa a partir de la cual se edifica un concepto de democracia más participativa, de hecho la libertad de los seres humanos cobra valor en sí misma en la medida que permite la participación en la toma de decisiones públicas, antes que un bien individual adquiere sentido como una herramienta del bien común. La concesión de derechos por parte del Estado se encuentra ligada al concepto de ciudadano antes que al de ser humano.

- Modelo de Ciudadanía Comunitarista: estrechamente vinculada al Estado Nacionalista, es explicada en extensión por Charles Taylor, David Miller y Michael Walzer. Implica una variación profunda con las anteriores formas ya que la participación del ciudadano en beneficio de su comunidad es una carga, una obligación que le viene dada por el hecho de pertenecer a ella, la consideración individual del ciudadano pierde relevancia frente a la preocupación por el bien de la comunidad, que justifica incluso la limitación de las libertades individuales. Ser ciudadano o no serlo se reduce a pertenecer o no a la comunidad, lo que genera un fuerte ejercicio de exclusión y desprecio hacia los extranjeros.

- Modelo de Ciudadanía Diferenciada: se desarrolla de mejor manera en el Estado social de derecho y contextos de democracias participativas y pluralistas. En los trabajos de Iris Young puede observarse la crítica a la paradoja de la democracia en cuanto a la decisión de las mayorías, en la medida en que más allá de la participación de los grupos diferenciados, se pretende la representación real de las 
necesidades de estos grupos en la toma de decisiones del Estado. Consecuentemente, el concepto de ciudadanía no puede continuar siendo un enfoque universalmente válido para todos los grupos que hacen parte de una sociedad considerada Estado; por ello, si bien se reconoce un estatus de derechos que integran el concepto de ciudadanía, también se reconoce la existencia de grupos de ciudadanos que por condiciones especiales necesitan un tratamiento jurídico, político y social diferente.

- Modelo de Ciudadanía Multicultural: es pensar en la existencia de una ciudadanía multicultural, que parte del reconocimiento de la existencia de Estados complejos y multiculturales en el sentido que coexisten en su interior diferentes naciones (multinacionalidad) o distintas etnias (polietnicidad). En tal sentido, un concepto de ciudadanía que solo abarque a la etnia o nación mayoritaria es incompleto, razón por la cual existe un número de derechos que se reconocen a la totalidad de miembros del Estado y otros que son derechos diferenciados, que le corresponden a las minorías étnicas o naciones diferentes que coexisten. Estos son derechos de autogobierno, derechos poliétnicos y derechos especiales de representación (Kymlicka, 1996).

- Modelo de Ciudadanía Posnacional: esta forma desarrollada ampliamente por Jürgen Habermas desborda el concepto de Estado nación, acercándose más a lo que puede entenderse como democracia global. Presupone un concepto de ciudadanía incluyente, que no distingue entre nacionales, no nacionales, minorías étnicas, etc. Habermas es reconocido por su teoría del patriotismo constitucional, cuando en rechazo del nacionalismo rescata el amor a la comunidad política democrática y al Estado de Derecho por encima de la nación. Se trata de una teoría que pretende mantenerse neutral frente a las consideraciones éticas y étnicas alrededor de las construcciones políticas. El concepto de bien común se entiende como aquello que es bueno para todos y no para "nosotros", dado que el pluralismo de las cosmovisiones de la sociedad actual es un pluralismo ético y étnico, que requiere de una neutralización de lo político, a fin de tratar de conservarlo y mantenerlo (Aguilera, 2011).

- Modelo de ciudadanía del Cosmopolitanismo Cívico: autores como David Held, Adela Cortina y Martha Nussbaun entienden la 
ciudadanía como un conjunto de deberes y derechos de contenido general, común, independiente de los Estados Nacionales; en este sentido se acerca a la Teoría del Patriotismo Constitucional. David Held (citado por Aguilera, 2011) presenta una crítica al concepto de ciudadanía nacional basado en el hecho de que, frente a la globalización, el reconocimiento de unos derechos individuales atribuidos solo dentro de los límites estatales es insuficiente, de hecho el desarrollo de una legislación internacional que protege mejor los derechos fundamentales es muestra de la insuficiencia del concepto de ciudadanía nacional.

Tabla 1. Resumen Modelos de Ciudadanía

\begin{tabular}{|c|c|c|c|}
\hline Modelo & Autores & $\begin{array}{c}\text { Relación entre ciudadanos } \\
y \text { Estados }\end{array}$ & $\begin{array}{c}\text { Forma de democracia y de } \\
\text { Estado }\end{array}$ \\
\hline Liberal & $\begin{array}{l}\text { Autores franceses del } \\
\text { siglo XVIII (Jean Jaques } \\
\text { Rousseau, Maximilien } \\
\text { Robespierre) }\end{array}$ & $\begin{array}{l}\text { Visión individual del ciu- } \\
\text { dadano }\end{array}$ & $\begin{array}{l}\text { Estados liberales moder- } \\
\text { nos europeos y democra- } \\
\text { cia representativa }\end{array}$ \\
\hline Republicana & $\begin{array}{l}\text { Hannah Arendt y Phi- } \\
\text { lip Pettit entre otros }\end{array}$ & $\begin{array}{l}\text { Visión del ciudadano co- } \\
\text { mo un ser deliberativo }\end{array}$ & $\begin{array}{l}\text { Estado naciente de la } \\
\text { Emancipación americana } \\
\text { de } 1776 \text { y democracias } \\
\text { participativas }\end{array}$ \\
\hline $\begin{array}{l}\text { Comunita- } \\
\text { rista }\end{array}$ & $\begin{array}{l}\text { Charles Taylor, Da- } \\
\text { vid Miller y Michael } \\
\text { Walzer. }\end{array}$ & $\begin{array}{l}\text { El estatus de ciudadano } \\
\text { depende de la pertenencia } \\
\text { a una comunidad. }\end{array}$ & Estados nacionalistas \\
\hline Diferenciada & Iris Young & $\begin{array}{l}\text { La ciudadanía es diferen- } \\
\text { cial, lo que habilita distin- } \\
\text { tos tratamientos. }\end{array}$ & $\begin{array}{l}\text { Estado Social de Dere- } \\
\text { cho Democracias radi- } \\
\text { cales }\end{array}$ \\
\hline \multirow[t]{2}{*}{ Multicultural } & \multirow[t]{2}{*}{ Will Kymlicka } & \multirow{2}{*}{$\begin{array}{l}\text { La ciudadanía abarca la } \\
\text { complejidad de los Estados } \\
\text { multinacionales y poliét- } \\
\text { nicos }\end{array}$} & $\begin{array}{l}\text { Sociedades democráticas, } \\
\text { participativas y pluralistas }\end{array}$ \\
\hline & & & Estado Social de Derecho \\
\hline Post Nacional & Jürgen Habermas & $\begin{array}{l}\text { La ciudadanía no distingue } \\
\text { entre nacionales, no nacio- } \\
\text { nales y minorías étnicas. }\end{array}$ & $\begin{array}{l}\text { Estados post nacionales y } \\
\text { democracia global }\end{array}$ \\
\hline $\begin{array}{l}\text { Cosmopolita- } \\
\text { nismo Cívico }\end{array}$ & $\begin{array}{l}\text { David Held, Adela } \\
\text { Cortina y Martha } \\
\text { Nussbaun }\end{array}$ & $\begin{array}{l}\text { La ciudadanía es un con- } \\
\text { junto de deberes y dere- } \\
\text { chos de contenido general } \\
\text { común independiente de } \\
\text { los Estados nacionales. }\end{array}$ & $\begin{array}{l}\text { Estados postnacionales y } \\
\text { democracia global }\end{array}$ \\
\hline
\end{tabular}

Fuente: elaboración propia. 
Finalmente, puede concluirse de manera parcial que la ciudadanía consiste en un núcleo de derechos, que no solo deben ser reconocidos sino también protegidos por el Estado y ejercidos por el individuo o los grupos. De igual forma, resulta claro que el modelo de ciudadanía que mejor asumiría las aspiraciones de un grupo tradicionalmente discriminado como lo es la población LGBTI sería la perspectiva de Iris Young de ciudadanías diferenciadas (Añon, 2001).

\section{Ciudadanía diferenciada, democracia radical y movimiento LGBTI}

Una perspectiva de ciudadanía que considera la diferencia encuentra perfecto desarrollo en democracias radicales ya que solo en ellas se efectúa el proceso de deconstrucción de la categoría porque reconoce que ella nace como un sistema de exclusión que simplifica lo universal desconociendo las diferencias. En la democracia radical, no basta simplemente el reconocimiento legal de los derechos, sino que más allá, interesa la manera como se ejercen los derechos e incluso el proceso que logró la institucionalización de los mismos:

una forma de identidad política que consiste en la identificación con los principios políticos de la democracia moderna pluralista, es decir, en la afirmación de la libertad y la igualdad para todos. Tendría que ser una identidad política común entre personas comprometidas en muy diversas empresas y con diferentes concepciones del bien, pero vinculadas las unas a las otras por su común identificación con una interpretación dada de un conjunto de valores ético-políticos (Mouffe, 1992, p. 8).

En este sentido la ciudadanía se convierte en una identidad articuladora (más no dominante), que permite la interacción entre diversas dimensiones de los sujetos como agentes sociales y como individuos; es una herramienta que engrana lo público y lo privado. Lo interesante de una posición desde la democracia radical, es que al mismo tiempo que se reivindica la diferencia se fortalece el trabajo mancomunado de todos los ciudadanos democráticos, comprometidos con un verdadero sistema justo para todos (sin lugar a discriminación negativa al interior del todos). Esta 
debe ser la verdadera apuesta común de los movimientos ciudadanos ${ }^{3}$, que parte del reconocimiento de identidades colectivas diferenciadas, pero no se agota en ellas mismas, sino que procede a un paso mayor que permite a las identidades colectivas movilizarse en un accionar conjunto.

El ejercicio pleno de los derechos de la ciudadanía LGBTI solo se garantiza en un contexto de democracia radical donde es importante reconocer las diferencias entre cada uno de los miembros de la comunidad como sujetos e incluso como colectividades (ya que es un grupo esencialmente diverso), reconocer la diferencia entre este grupo y otros como mujeres, afro e indígenas que también han sido excluidos e identificar las apuestas comunes entre el movimiento LGBTI y estos para iniciar una acción colectiva mancomunada, que potencialice los efectos y los logros socio-políticos.

\section{Acción e identidad colectiva: Los nuevos movimientos sociales como agentes de cambio}

El estudio de los movimientos sociales representa una forma diferente de entender la sociedad, dejando de lado el análisis estructural y la estricta lógica de las clases sociales retoma la importancia de los sujetos y de la acción colectiva en los procesos de producción y reproducción de la sociedad. Al respecto, la teoría de Alain Touraine denominada comúnmente accionalismo, ofrece una forma dinámica de entender las construcciones y la manera como históricamente se determinan los poderes y valores culturales. La teoría de los movimientos sociales, llena un vacío que existía en la sociología, incapacitada anteriormente para explicar las dinámicas que se tejen alrededor de los nuevos actores sociales y la manera como su acción colectiva modifica las condiciones y los contextos.

3 Según Chantal Mouffe (1992) "esto indica el reconocimiento común por los diferentes grupos que luchan por una extensión y radicalización de la democracia, de que tienen una preocupación común, y llevará a la articulación de las demandas democráticas que enarbolan diferentes movimientos: las mujeres, los trabajadores, los negros, los homosexuales, los ecologistas, lo mismo que otros 'movimientos sociales nuevos'. El objetivo es construir un "nosotros" como ciudadanos democráticos radicales, una identidad política colectiva articulada mediante el principio de equivalencia democrática. Debe ser subrayado que tal relación de equivalencia no elimina las diferencias - lo contrario sería simple identidad-. Es solo en la medida en que las diferencias democráticas se oponen a las fuerzas o discursos que niegan a todas ellas, que esas diferencias serán sustituíbles entre si" (p. 9). 
Touraine (citado por Orozco, 2000) entiende al actor social como el ciudadano, inseparable de su desarrollo personal y del progreso social, en el que la libertad individual y la participación colectiva se encuentran íntimamente ligadas. Así mismo, explica la existencia de tres principios: principio de identidad, según el cual el actor posee una definición de sí mismo y adquiere una distinción respecto de los otros que coexisten en un mismo escenario; principio de oposición, que plantea la existencia del conflicto como atmósfera necesaria para el desarrollo social, en la que cada movimiento social reconoce e interactúa directamente con su adversario; principio de totalidad, que expresa la idea de la existencia de un sistema de acción histórica de disputa de los diferentes actores por el dominio cultural. Consecuentemente, los movimientos sociales son una acción conflictiva de agentes que luchan por el control del Sistema de acción histórica, nuevas formas de organización social y de vida cultural portadoras de un nuevo orden social, valores y poder.

A partir del accionalismo, y de las tesis de variados autores como Melucci, Castells y Lojkine, no tendría sentido entrar a discutir hoy la importancia de los movimientos sociales en el desarrollo de las sociedades ${ }^{4}$; estos son verdaderos agentes transformadores, constructos, productos de un proceso de reconocimiento de identidades colectivas, de marcación de asuntos e intereses comunes para redistribuir las condiciones que se perciben injustas para un grupo significativo. Entonces los movimientos sociales no son expresiones colectivas al azar, son el producto de diversas interrelaciones humanas de consensos y tensiones internas, que han determinado de manera más o menos permanente, no solo por qué pertenecer sino también el para qué hacerlo. Los movimientos sociales no son las protestas ni las organizaciones que surgen con ocasión de las protestas, son un conjunto de individuos con una identidad colectiva que subyace a la expresión (Melucci, 1999).

De lo anterior se infiere claramente la importancia que tienen los movimientos sociales para el reconocimiento e institucionalización de las ciudadanías diferenciadas como herramienta emancipadora y de

\footnotetext{
4 Situación que no siempre ha sido - en la medida que en los tiempos de la sociología clásica e incluso desde la escuela sociológica norteamericana, los movimientos sociales fueron confundidos con las conductas desviadas, llegándose a afirmar que en las acciones colectivas se pierde la posibilidad de razonar- la actuación del ser humano como masa.
} 
deconstrucción de los modelos de subordinación cultural. En un contexto de democracia radical la acción colectiva debe ser protegida e impulsada, en la medida que constituye una entidad capaz de movilizar las estructuras que por su vocación de ser estáticas corren el riesgo de ser excluyentes. Los movimientos sociales a través de su acción visibilizan necesidades de amplitud de garantías ciudadanas; así, por ejemplo, es solo por medio de las demandas de los movimientos sociales de reivindicación de derechos de las mujeres, que se han logrado reconocer medidas de discriminación positiva para favorecer su participación política en todos los Estados donde estas se han promulgado.

\section{La acción colectiva y el movimiento LGBTI}

El movimiento social que se ha originado alrededor de la lucha por el reconocimiento y garantía de la ciudadanía LGBTI es catalogado como uno de los llamados "nuevos movimientos sociales", ligados especialmente a la democratización de los derechos humanos. Según Delgado (2007) el concepto hace referencia a un conjunto de formas de acción colectiva diferentes a aquellas basadas en las clases, que sirve para designar un enfoque centrado en la construcción relacional que implica la acción colectiva y en la relevancia de los elementos culturales ligados a la creación de marcos interpretativos y a la definición de las identidades, también colectivas.

Suele identificarse históricamente como momento naciente del movimiento LGBTI los disturbios de Stonewall el 28 de junio de 1969 en la ciudad de Nueva York; más que un hecho ocasional se trataba de la verdadera manifestación de un movimiento social que expresó el inconformismo con el que se habían constituido en prácticas sociales y normativas las restricciones a su identidad. Esta manifestación no surge solo del sentimiento transitorio de injusticia, sino del desarrollo de posturas disconformes y reivindicatorias desde el siglo XIX que iniciaron en Alemania, en el periodo anterior al tercer Reich, ideología que poco a poco fue colonizando otros territorios y que entradas las primeras décadas del siglo XX penetró en la sociedad norteamericana; ya en el año 1924 el inmigrante Alemán Henry Gerber había fundado en Chicago la 
primera asociación homosexual de Estados Unidos ${ }^{5}$, que incluso sostenía una revista.

Lo cierto es que los disturbios de Stonewall marcaron un punto de inflexión en el movimiento social de transformación de sus fines y estrategias ${ }^{6}$, pero de ninguna forma constituyen solo un registro histórico aislado, hacen parte de la estructura construida desde el siglo XIX. Esta modificación de objetivos es posible porque la acción colectiva de los medios sociales depende tanto de los medios, los recursos y el ambiente, como de los fines del mismo. Luego de establecidas las nuevas condiciones sociales, el movimiento LGBTI se pudo transformar de la mano del triunfo de otras acciones colectivas tales como los movimientos pacifistas, feminista y afro de la sociedad norteamericana de la época. Era una especie de generalización de la insatisfacción que pudo ser aprovechada por distintos movimientos sociales, no solo por el movimiento LGBTI.

El movimiento LGBTI en Colombia, su acción colectiva y el asunto de la identidad

En Colombia el Colectivo León Zuleta en el texto "Historia del Movimiento Gay en Colombia" (s.f.) menciona como origen del movimiento LGBTI la integración del grupo "Los Felipitos"; sin embargo, el mismo texto reconoce que antes que un movimiento era una especie de club privado para socializar. Las gestas del movimiento social se dieron realmente en los años 70, producto de la interacción con lo que ocurría en otras latitudes, específicamente en Norteamérica:

No fue sino en 1970 que un nuevo grupo fundado por León Zuleta apareció en la ciudad de Medellín. Luego se expandió a Bogotá cuando Zuleta conoció a Manuel Velandia, en ese entonces estudiante de Filosofía y Psicología. Un grupo llamado Movimiento por la Liberación Homosexual se formó entonces. Este organizó varias actividades, como la primera marcha gay y la primera publicación gay en el país, Ventana Gay. Después de varios años, y por diferentes razones, el movimiento se acabó a mediados de los años 80 (Colectivo León Zuleta, s.f., p. 1).

5 The Society for Human Rights.

6 Sus primeras luchas fueron por la aceptación, ahora son por la reafirmación y el reconocimiento de derechos en pie de igualdad con las demás formas de orientación sexual. 
En 1981 se despenalizó en Colombia la homosexualidad, un año después se produce la primera marcha del orgullo gay. Al iniciar la década de los 90, quizás por la coyuntura de la finalización de un largo periodo de dominio del narcotráfico, lo que permite a la sociedad pensar en otras dinámicas, y la fuerte tendencia inclusiva de la Constitución Política de 1991, el movimiento del orgullo gay colombiano se hace mucho más activo con con la finalidad de la aceptación, sino de la reivindicación de su ciudadanía en condiciones de igualdad, valiéndose de estrategias tales como las manifestaciones públicas, el arte urbano y la defensa judicial, especialmente a través de acciones de tutela, de una serie de asuntos considerados prioritarios.

El movimiento LGBTI ha sido relevante en el proceso de democratización del Estado colombiano pues ha contribuido al reconocimiento de diferentes tipos de familia y a la reafirmación de las libertades individuales, aspectos que repercuten en beneficio de cualquier ciudadano; ya que si bien una acción colectiva es un empresa que busca un fin común, este también favorece a toda la sociedad, de ello deviene la legitimidad del fin, que sea acorde con las sociedades democráticas, participativas y pluralistas, con los ideales, principios y valores del Estado social de derecho.

Otro asunto que queda por analizar, es el componente de la identidad colectiva que se entiende inmerso en los movimientos sociales. La formación de una identidad colectiva es un proceso necesario de tensiones, conflictos y acuerdos entre las diferentes identidades que confluyen en un movimiento social. La construcción social de lo colectivo es permanente, de tal forma que la ruptura o fracaso de este proceso impide la acción (Melucci, 1999), lo que sería fatal para cualquiera porque es esta identidad la que atribuye significados a las problemáticas y temáticas seleccionadas por el grupo de individuos; es la que le permite interpretar las realidades y le da la razón a la acción, de ahí la necesidad de desarrollar lazos de solidaridad entre los miembros del movimiento a fin de que sean capaces de compartir.

En palabras de Ricardo Delgado (2007) la identidad colectiva es una definición compartida, interactiva, producida por varios individuos a un nivel más complejo, que está relacionada con las orientaciones y los significados de la acción y con el campo de oportunidades y construcciones donde tiene lugar. 
En tratándose del movimiento LGBTI la formación de esta identidad colectiva está atravesada por las diferentes orientaciones sexuales e identidades de género que representa; de hecho desde los problemas de la definición de cada una de las letras de la sigla que conforman el nombre, hasta el orden de ellas en la misma, es un asunto de conformación de una identidad colectiva sujeta a múltiples tensiones.

El problema de la sigla parece trivial pero en realidad demarca una fuerte conflictividad en el proceso de elaboración de la identidad colectiva LGBTI, se plantea por ejemplo la necesidad de incluir la Q (queer) en ella o de eliminar la sigla y reemplazarla por Sexualidades diversas o la necesidad de mantenerla como asunto simbólico de un movimiento de reivindicación de derechos, que no pretende excluir a ninguna forma de sexualidad, sino constituirse en una apuesta común de luchas.

El problema de fondo es la falta de apropiación de algunos individuos de la identidad colectiva, que hacen evidente, por ejemplo, que actualmente el asunto "gay" parece circunscribirse al derecho al matrimonio y a las familias homoparentales, cuando las necesidades prioritarias de las personas transgénero en realidad están en el acceso a la educación, oportunidades laborales dignas, seguridad social y una legislación en salud que cubra las transformaciones corporales que requieren para lograr una imagen física que coincida con su identidad de género. De la misma forma, los movimientos lésbicos denuncian la existencia de grupos gays misóginos, elitistas y machistas; en otras palabras, se trata de endodiscriminación de género en el movimiento social. Incluso algunos grupos desestiman la necesidad de etiquetarse a fin de ser reconocidos como miembros de una de las letras que incorpora la sigla.

\section{Conclusiones}

La categoría de ciudadanía que se edificó desde la antigua Grecia y aún hasta mediados del siglo Xx es una especialmente excluyente, ya sea a partir del concepto de "unos" a quienes se les reconoce o desde el "todos" a quienes se les reconoce, siempre ha aparecido como una categoría condicionada y de la que algunos grupos de individuos han 
sido excluidos en la medida en que no se corresponde con el concepto de ser humano, que sí abarca a la totalidad.

Puede hablarse incluso de la existencia de un sistema estratificado de ciudadanía, que distingue ciudadanos, ciudadanos no plenos y no ciudadanos. Los ciudadanos plenos tendrían tanto el reconocimiento institucional de sus derechos como el ejercicio libre de los mismos, mientras que los no plenos a pesar del reconocimiento formal encuentran su ejercicio limitado; finalmente, los no ciudadanos carecen incluso del reconocimiento formal. El proceso histórico ha demostrado que la movilización de una categoría a otra normalmente se realiza en escenarios de conflicto, en los que los movimientos sociales se constituyen como verdaderos motores de cambio.

En este sentido, es necesario reconocer que las gestas de los movimientos sociales representan un punto de inflexión para el desarrollo de sociedades más democráticas que garanticen el progreso del ser humano en toda su extensión, alcance y complejidad; comprender que el reconocimiento de los derechos del campesinado no implica el desconocimiento de derechos de los industriales o que la reafirmación de derechos de las mujeres no implica detrimento de los derechos de los hombres, y concretamente que generar un sistema de normas que reconoce la diversidad sexual y de identidad de género como una categoría de inclusión y no de exclusión fortalece la condición de ciudadanos, al mismo tiempo que fortalece la identidad colectiva LGBTI.

Solo de esta manera es posible practicar una verdadera democracia radical que comprende y es coherente con el hecho que los derechos humanos limitan el poder soberano, por tanto no es entendible que desde los mismos ciudadanos se restrinja la posibilidad de tal limitación. La acción colectiva LGBTI reafirma el derecho de todos y cada uno de los seres humanos a ser iguales ante la ley, a desarrollar su personalidad de manera libre, a formar una familia, a controlar su cuerpo, a gozar de garantías y seguridad social, a escoger su profesión y oficio, y a expresar su identidad, entre otros. Razón por la cual, es necesario fortalecer categorías tales como género-sensitivos, heterosolidarios, nuevas masculinidades, en fin, todas las que actualmente designan aquellos individuos que sin ser parte de la identidad colectiva comparten los objetivos de la misma 
porque son conscientes de la necesidad de democratizar las relaciones entre Estado y ciudadanía en Colombia.

\section{Referencias}

Aguilera, E. (2011). La ciudadanía ante la globalización: nuevos modelos de ciudadanía postnacional y transcultural. Revista de Derecho UNED (8), 3-48.

Añón, M. J. (2001). Igualdad, Diferencias y desigualdades. (1 era ed.). México: Distribuciones Fontanera S.A.

Cortina, A. (2013). Ciudadanos del Mundo: hacia una teoría de la ciudadanía. (3era ed.) Madrid: Alianza Editorial.

Colectivo León Zuleta (s.f.). Historia del Movimiento Gay en Colombia. Recuperado de http://cf.caribeafirmativo.lgbt/todo/ATT1379704196.pdf

Delgado, R. (julio-diciembre de 2007). Los marcos de acción colectiva y sus implicaciones culturales en la construcción de ciudadanía. Revista Universitas Humanística. (64), 41-66.

Ferrer, N. (2010). El Acceso a la Justicia como elemento indispensable del ejercicio de la ciudadanía femenina. Revista Opinión Jurídica, 9, 13-124.

Horach, J. (2009). Sobre el concepto de ciudadanías: historia y modelos. Factótum. Revista Filosófica (6), 1-22. Recuperado de: http://www.ses.unam.mx/ curso2015/pdf/25sep-Horrach.pdf

Kymlicka, W. (1996/2010). Ciudadanía Multiucultural. (6. ${ }^{\text {ta }}$ reimpresión). Madrid: Paidós.

Marshall, T. (1950). Ciudadanía y clase social. Recuperado de http://catedras.fsoc. uba.ar/isuani/marshall.pdf

Melucci, A. (1999). Acción colectiva, vida cotidiana y democracia. En Teoría de la Acción Colectiva, (pp. 25-54). México: El Colegio de México. Recuperado de http://www.ses.unam.mx/docencia/2016II/Melucci1999_AccionColectivaVidaCotidianaYDemocracia.pdf

Mouffe, C. (1992). Ciudadanía, identidad y democracia radical. En Unifem e Instituto Federal Electoral (Comps.) Ciudadanía y feminismo. México: Debate Feminista.

Orozco, M. (2000). Alain Touraine: teoría de los movimientos sociales. (Tesis de licenciatura, Universidad Autónoma de Metropolitana, Iztapalapa, México). Recuperado de: http://tesiuami.izt.uam.mx/uam/aspuam/presentatesis. php?recno=1484\&docs $=$ UAM1484.PDF 